\title{
Horizontally resolved structures of radar backscatter from polar mesospheric layers
}

\author{
R. Latteck, W. Singer, M. Rapp, T. Renkwitz, and G. Stober \\ Leibniz Institute of Atmospheric Physics at the Rostock University, Schloss-Str. 6, 18225 Kühlungsborn, Germany \\ Correspondence to: R. Latteck (latteck@iap-kborn.de)
}

\begin{abstract}
The Leibniz-Institute of Atmospheric Physics in Kühlungsborn, Germany (IAP) installed a new powerful VHF radar on the North-Norwegian island Andøya $\left(69.30^{\circ} \mathrm{N}, 16.04^{\circ} \mathrm{E}\right)$ from 2009 to 2011 . The new Middle Atmosphere Alomar Radar System (MAARSY) replaces the existing ALWIN radar which has been in continuous operation on Andøya for more than $10 \mathrm{yr}$. MAARSY is a monostatic radar operated at $53.5 \mathrm{MHz}$ with an active phased array antenna consisting of 433 Yagi antennas each connected to its own transceiver with independent control of frequency, phase and power of the transmitted signal. This arrangement provides a very high flexibility of beam forming and beam steering. It allows classical beam swinging operation as well as experiments with simultaneous multiple beams and the use of modern interferometric applications for improved studies of the Arctic atmosphere from the troposphere up to the lower thermosphere with high spatial-temporal resolution. The installation of the antenna was completed in August 2009. An initial expansion stage of 196 transceiver modules was installed in spring 2010, upgraded to 343 transceiver modules in December 2010 and the installation of the radar was completed in spring 2011. Beside standard observations of tropospheric winds and Polar Mesosphere Summer Echoes, multi-beam experiments using up to 91 beams quasisimultaneously in the mesosphere have been carried out using the different expansion stages of the system during campaigns in 2010 and 2011. These results provided a first insight into the horizontal variability of Polar Mesosphere Summer and Winter Echoes in an area of about $80 \mathrm{~km}$ by $80 \mathrm{~km}$ with time resolutions between 3 and $9 \mathrm{~min}$.
\end{abstract}

\section{Introduction}

The phenomenon of strong radar echoes from the mesopause region during summer is well known from VHF radar observations at polar and middle latitudes for more than $30 \mathrm{yr}$.
These so-called Polar Mesosphere Summer Echoes (PMSE) are caused by inhomogeneities in the electron density of a size comparable to the radar Bragg scale in presence of negatively charged aerosol particles. An overview on the current understanding of this phenomenon has been published by Rapp and Lübken (2004).

Similar echoes can be detected by VHF radars during the winter months in the mid mesosphere from $\sim 55-85 \mathrm{~km}$ altitude. Due to their similarity in observation method and location to PMSE these echoes were named polar mesosphere winter echoes (PMWE) (Czechowsky et al., 1979; Ecklund and Balsley, 1981; Kirkwood et al., 2002). PMWE are much less frequent than their summer counterparts (Zeller et al., 2006) and the underlying physics is currently debated (Lübken et al., 2006; Kirkwood et al., 2006) and subject of current active research.

In this study we present the first 3-dimensionally resolved observations of PMSE and PMWE obtained during the construction period of the Middle Atmosphere Alomar Radar system (MAARSY). The design and functionality of both the initial and second stage of extension of MAARSY used for this observation are described.

\section{System description}

MAARSY is a monostatic radar located on the NorthNorwegian island Andøya $\left(69.30^{\circ} \mathrm{N}, 16.04^{\circ} \mathrm{E}\right)$. The radar is designed for atmospheric studies from the troposphere to the lower thermosphere, especially for the investigation of horizontal structures of PMSE. The general idea of MAARSY has been presented by Latteck et al. (2010).

The system is composed of an active phased antenna consisting of 433 array elements and an identical number of transceiver modules. The operational radar frequency is $53.5 \mathrm{MHz}$ and the maximum peak power is approximately $800 \mathrm{~kW}$. The 433 3-element linear polarized Yagi antennas 

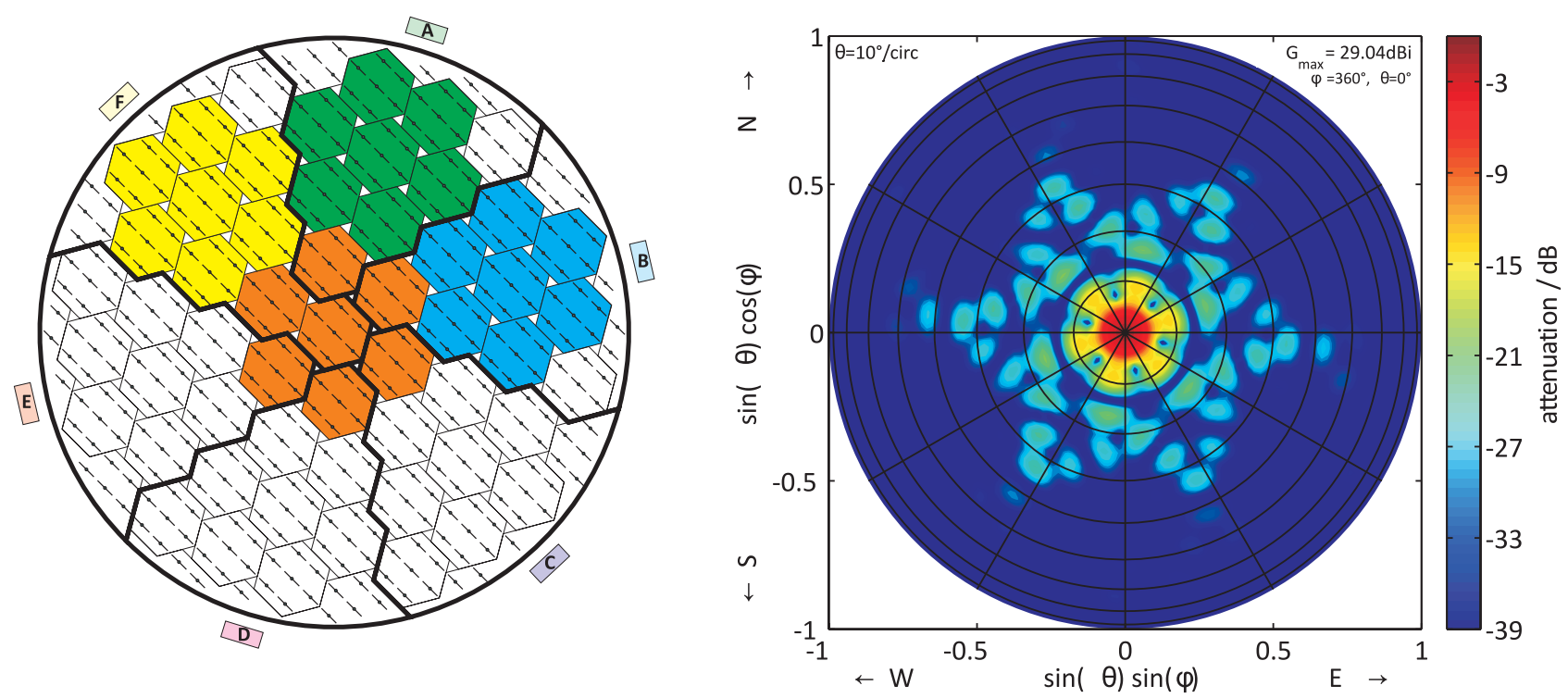

Fig. 1. Initial expansion stage of MAARSY as installed in May 2010. Antenna subgroups connected to transceiver modules are highlighted in color in the left panel. Three antenna structures (green, blue, orange) were used to form a central symmetric antenna beam with a half power beam width of $6^{\circ}$ for classical Doppler beam steering. A computed radiation pattern for a beam pointing to $0^{\circ}$ (zenith) is shown in the right panel. The receiving signals related to the individual hexagon antenna structures marked in yellow were connected to 7 receivers and used for spaced antenna experiments in the mesosphere.

arranged in an equilateral triangle grid structure with a spacing of $4 \mathrm{~m}$ forms a nearly circular antenna array with a diameter of approximately $90 \mathrm{~m}$ corresponding to an aperture of $\sim 6300 \mathrm{~m}^{2}$. The symmetric antenna radiation pattern of the array has a beam width of $3.6^{\circ}$ (full width at half power), a directive gain of $33.5 \mathrm{dBi}$ and an almost symmetric first sidelobe with more than $17 \mathrm{~dB}$ suppression with respect to the main lobe.

Each antenna of the array is connected to its own transceiver module individually controllable in frequency, phase, and gain settings on a pulse-to-pulse basis. This arrangement allows very high flexibility of beam forming and beam steering with a symmetric radar beam and arbitrary beam pointing directions.

On reception the antenna array can be divided in 61 subarrays, 55 of them are symmetrical structures (hexagon) consisting of 7 antennas each, 6 subgroups consisting of 8 antennas each are located at the perimeter of the array. 7 adjacent hexagonal structures as e.g. indicated by the colored areas in the left panel of Fig. 4 can be further combined to 7 so called "anemone" antenna structures. Each receiving signal of a hexagonal or anemone antenna sub-structure can be selected as an input of a 16 channel data acquisition unit. This allows a wide range of receiving arrangements with different antenna configurations for interferometric or multi-receiver applications. Additionally, separately located receiving antennas used for e.g. interferometer observations of meteors or for boundary layer observations can be switched to the data acquisition via an antenna interface unit.
A detailed technical description of MAARSY is given by Latteck et al. (2012).

\section{3-D resolved structures of mesospheric echoes obtained during the construction period of MAARSY}

The construction of the MAARSY antenna array and the infrastructure for radar control and communication was completed in August 2009. The radar control hardware for synchronization, triggering and communication needed in each of the six equipment buildings, the master control system, an interim design of the combining unit and the data acquisition hardware housed in the main building was installed during winter 2009/2010. The radar operation started with an initial expansion of 196 transceiver modules in May 2010. A second stage of expansion to 343 transceiver modules was brought into service in November 2010. First results using the two stages of extension during campaigns in summer and December 2010 are presented here to demonstrate the performance and functionality of the new radar during the construction period.

\subsection{Results using the initial stage of expansion}

\subsubsection{Design of the initial stage of expansion}

The installed transceiver modules of the initial expansion stage were connected to antenna subgroups as highlighted in color in Fig. 1. Three anemone antenna structures as 

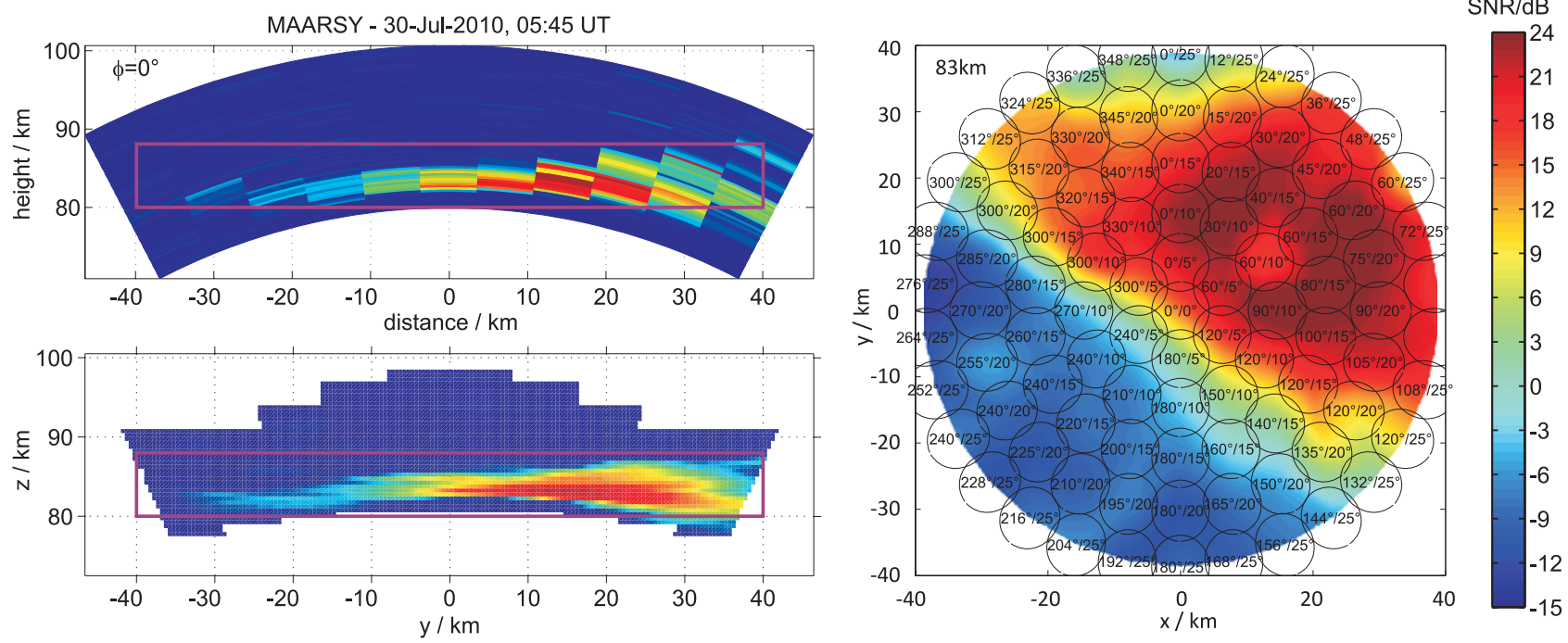

Fig. 2. Vertical and horizontal structure of a PMSE observed with 91 beams quasi-simultaneously on 30 July 2010 . The upper left plot shows the SNR determined from observations along the North-South axis $\left(\varphi=0^{\circ}\right)$ using 10 beams changing off-zenith angle after 4 coherent integrations. The lower left panel depict the same situation but interpolated to a grid with $500 \mathrm{~m}$ horizontal and vertical resolution. The right plot shows a slice at $83 \mathrm{~km}$ height through the 3-dimensional interpolated data obtained from all 91 beams. The tagged ovals overlayed on the contour plot mark the areas at $83 \mathrm{~km}$ altitude illuminated by the beams.

Table 1. Allocation of MAARSY antenna structures to the inputs of the signal processing unit as used with the initial and second stage of expansion. Single capital letters indicate anemone structures as e.g. $\mathrm{A}=$ "anemone A", "F-xx" stands for a selected hexagon of anemone F. "Met-xx" and "But-xx" are signals from separate located antennas as from the meteor antennas and the Butler array (Renkwitz et al., 2011).

\begin{tabular}{ccc}
\hline $\begin{array}{c}\text { signal processing } \\
\text { unit inputs }\end{array}$ & $\begin{array}{c}\text { initial stage } \\
\text { of expansion }\end{array}$ & $\begin{array}{c}\text { second stage } \\
\text { of expansion }\end{array}$ \\
\hline 01 & Met-01 & A \\
02 & Met-02 & B \\
03 & Met-03 & C \\
04 & Met-04 & D \\
05 & Met-05 & E \\
06 & A & F \\
07 & B & A+B+C+D+E+F+M \\
08 & M & But-01 \\
09 & F-01 & But-02 \\
10 & F-02 & But-03 \\
11 & F-03 & But-04 \\
12 & F-04 & But-05 \\
13 & F-05 & But-06 \\
14 & F-06 & But-07 \\
15 & F-07 & But-08 \\
16 & A+B+M &
\end{tabular}

marked in green, cyan and orange $(\mathrm{A}, \mathrm{B}$, and $\mathrm{M})$ representing 147 antennas connected to transceiver modules were used to form a central symmetric antenna beam with a half power beam width of $6^{\circ}$ for transmission at an effective peak power of $\sim 218 \mathrm{~kW}$. On reception the combined IF signals of the anemone structures A, B and $\mathrm{M}$ were split and one half of the three split signals were combined and connected to signal processing channel 16 to be used in Doppler beam swinging (DBS) mode. The other half of the split anemone signals were led to three individual signal processing channels and used as spaced antennas (SA) in tropospheric experiments. Additionally to these three SA channels the seven IF signals belonging to the hexagons of equipment building $\mathrm{F}$ as marked in yellow in Fig. 1 were connected to further seven signal processing channels to be used as spaced antennas for mesospheric experiments. The allocation of the antenna structures to the signal processing channels is summarized in Table 1.

The data acquisition unit used with the 2010 partial expansion stages of MAARSY was capable to sample 8 dual channels only. Hence a multiplexer was used to switch the 16 dual outputs of the base band down converters to the 8 dual inputs of the digitizers.

\subsubsection{Experiment description}

MAARSY was designed for middle atmosphere studies, especially the investigation of horizontal structures of PMSE. In order to scan the atmosphere with a number of radar beams, the transceivers can store up to 50 parameter settings for e.g. phase offsets for beam pointing, and the parameters can be changed with the PRF. Due to limitations in the maximum data rate of the acquisition system used with the partial 
installations in 2010, it was not possible to operate a single experiment configured with 50 different beam directions and full coverage of the PMSE altitudes in summer 2010. Hence a sequence of experiments each configured for a reduced number of beam directions was used to perform first horizontal scans of PMSE in a quasi-simultaneous mode.

The maximum data rate and a sufficient coverage of altitude range around $85 \mathrm{~km}$ resulted in a experiment configuration as summarized in Table 2. Nine identical experiments with 10 different oblique beam directions each were configured. The vertical beam position was added to one experiment. The overall 91 beam positions are tagged to ovals indicating the illuminated areas at $83 \mathrm{~km}$ and overlayed on a contour plot of SNR in the right panel of Fig. 2. The beam position was changed after every 4 coherent integrations during the experiments runtime of $30 \mathrm{~s}$ and $33 \mathrm{~s}$, respectively. The whole sequence of 9 experiments illuminated an area of about $80 \mathrm{~km}$ diameter at an altitude range between $77 \mathrm{~km}$ and $88 \mathrm{~km}$. The scanning experiments were followed by a standard mesospheric experiment running for $35 \mathrm{~s}$ and covering a wider range in vertical direction with a larger number of coherent integrations. The total overall sequence runtime, corresponding to the time resolution of the scan, was $503 \mathrm{~s}$ due to additional time required for the reconfiguration of the hardware between the experiments.

\subsubsection{3-D resolved structures of PMSE}

A first mesospheric scan experiment using the described experiment sequence was conducted from 30 July until $4 \mathrm{Au}$ gust in 2010. The height-distance-intensity plot in the upper left panel of Fig. 2 shows an example of signal-to-noise ratio (SNR) obtained with with 11 beams along the North-South direction on 30 July 2010. The color coded areas represent vertical slices of the radar pulse volumes illuminated by the 11 beams with $300 \mathrm{~m}$ radial resolution. The range information of the profiles were first converted to altitude using the nominal off-zenith angle of the corresponding beams, then interpolated to a vertical grid with a resolution of $100 \mathrm{~m}$ and the resulting altitude values were converted back to ranges. The new polar coordinates of the interpolated data were then converted to cartesian coordinates and finally interpolated to a 2-dimensional horizontal grid with a equal resolution of $100 \mathrm{~m}$. The lower left panel of Fig. 2 shows the resulting 2-dimensional vertical slice of SNR corresponding to the example shown in the upper left panel. The pink frames in both plots mark the area which is zoomed in and presented in the upper right panel of Fig. 3.

The horizontal slice through the PMSE at $83 \mathrm{~km}$ depicted in the right panel of Fig. 2 shows a sharp decrease of SNR of about $30 \mathrm{~dB}$ along a $120^{\circ}$ to $300^{\circ}$ axis. A stack of horizontal slices at different altitudes and a zoomed vertical intersection of the same example all with $100 \mathrm{~m}$ horizontal and vertical resolution are presented in Fig. 3. The 3-dimensional resolved PMSE shows a maximum or core located north-
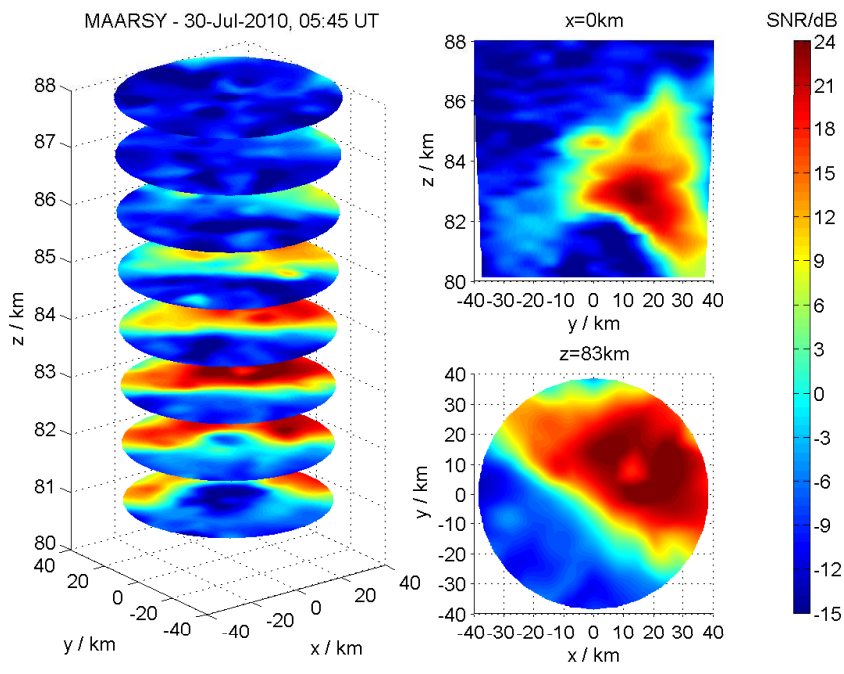

Fig. 3. 3-D structure of a PMSE quasi-simultaneously observed with 91 beams on 30 July 2010.

Table 2. Parameters of MAARSY experiments used for horizontal scanning of PMSE in August 2010 and PMWE in December 2010. The values in brackets correspond to the one experiment configured for 11 beam directions.

\begin{tabular}{lll}
\hline Period & $08 / 2010$ & $12 / 2010$ \\
\hline Pulse repetition frequency & $1400 \mathrm{~Hz}$ & $1250 \mathrm{~Hz}$ \\
No. of coherent integrations & 4 & 4 \\
Wave form (pulse coding) & 8 bit coco & 8 bit coco \\
Sub-pulse length & $2 \mu \mathrm{s}$ & $2 \mu \mathrm{s}$ \\
Pulse length & $16 \mu \mathrm{s}$ & $16 \mu \mathrm{s}$ \\
$\rightarrow$ Inter pulse period & $714.9 \mu \mathrm{s}$ & $800 \mu \mathrm{s}$ \\
$\rightarrow$ Effective PRF & $700 \mathrm{~Hz}$ & \\
$\rightarrow$ Duty cycle & $2.24 \%$ & $2 \%$ \\
Sampling start range & $77.1 \mathrm{~km}$ & $65.1 \mathrm{~km}$ \\
Sampling end range & $97.5 \mathrm{~km}$ & $85.5 \mathrm{~km}$ \\
Sampling resolution & $300 \mathrm{~m}$ & $300 \mathrm{~m}$ \\
$\rightarrow$ range gates & 69 & 77 \\
No. of data points p. exp. & $20480(22528)$ & 14336 \\
No. of beam directions & $10(11)$ & 7 \\
$\rightarrow$ No. of data pts. p. beam & 512 & 1024 \\
$\rightarrow$ Time resolution $\Delta t$ & $57.1 \mathrm{~ms}(62.9 \mathrm{~ms})$ & $22.4 \mathrm{~ms}$ \\
$\rightarrow$ Nyquist frequency & $8.75 \mathrm{~Hz}(7.95 \mathrm{~Hz})$ & $22.32 \mathrm{~Hz}$ \\
$\rightarrow$ Experiment runtime & $29.3 \mathrm{~s}(32.2 \mathrm{~s})$ & $22.9 \mathrm{~s}$ \\
No. of experiments & 9 & 4 \\
\hline
\end{tabular}

eastward of the radar location. This indicates that PMSE or the underlying structures and processes reveal a pronounced spatial variability that asks for in-depth studies in the future. 

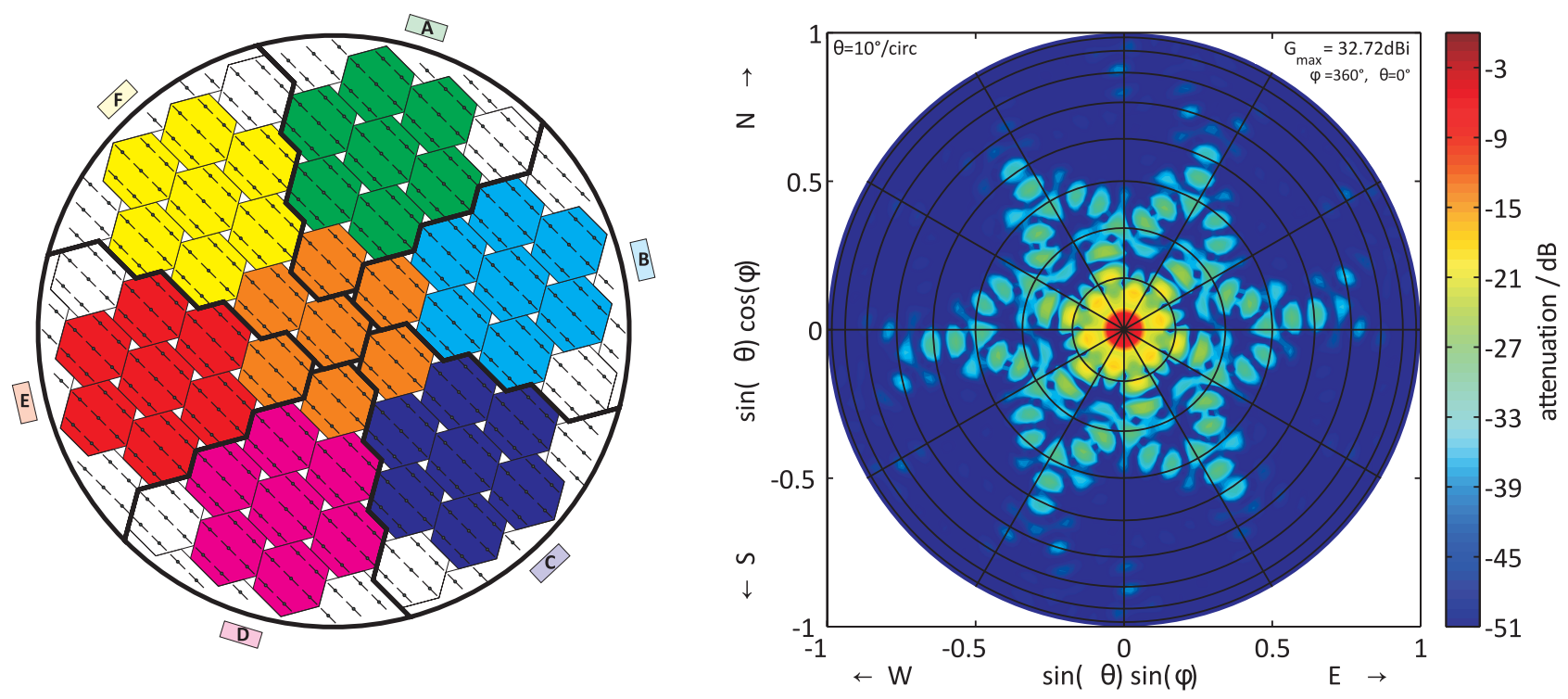

Fig. 4. Second expansion stage of MAARSY as installed in November 2010. 343 antennas of the colored hexagon structures as shown in the left panel were connected to transceiver modules and formed a radar beam with a half power beam width of $4^{\circ}$ for Doppler beam operation. The computed radiation pattern for a beam pointing to $0^{\circ}$ (zenith) using these seven anemones is shown in the right panel. The combined IF signals related to the seven anemone antenna structures (green, cyan, blue, magenta, red, yellow and orange) were connected to seven receivers and used for spaced antenna experiments in the troposphere.

\subsection{Results using the second stage of expansion}

\subsubsection{Design of the second stage of expansion}

After completion of the 2010 summer campaign for PMSE observation further transceiver modules were installed in November 2010. The second stage of expansion contained 343 transceivers connected to antennas as marked by colored hexagon structures in Fig. 4. The symmetrical setup formed a radar beam with a half power beam width of $\sim 4^{\circ}$ for transmission. On reception the combined signals related to the seven anemone antenna structures A, B, C, D, E, F and M as marked in green, cyan, blue, magenta, red, yellow and orange, respectively, were split and connected to seven signal processing channels as shown in Table 1 . The total combined receiving signal of all seven anemone antenna structures was led to signal processing channel 8 . The upper eight inputs $9 . .16$ of the signal processing units were connected via AIU to eight output ports of the 16 channel Butler matrix as described in detail in Renkwitz et al. (2011).

\subsubsection{3-D resolved structures of polar mesosphere winter echoes}

The new allocation of eight combined receiving signals corresponding to seven anemone structures and the full array to eight signal processing inputs allowed a non-multiplexing operation of MAARSY since December 2010. Since PMWE are a rare phenomenon with much shorter occurrence rate than PMSE a sequence of four experiments with six different oblique beam directions and a vertical beam was used in a sequence in order to reduce the sequence runtime for a quasi-simultaneous 3-D-scan. The detailed experiment configuration is summarized in Table 2. The four scanning experiments pointing to 25 different beam directions in total ran one after another with $23 \mathrm{~s}$ runtime each. The scan was followed by a standard mesospheric monitor experiment with $27 \mathrm{~s}$ runtime using a vertical beam only but a larger number of coherent integrations and range gates. The overall sequence runtime was $189 \mathrm{~s}$ due to the additionally needed times for experiment reconfiguration. The reduced number of beam directions (25) compared to the PMSE scanning experiment (91, see Sect. 3.1.3) reduced the illuminated area to about $40 \mathrm{~km}$ diameter in the altitude range of interest between $65 \mathrm{~km}$ and $82 \mathrm{~km}$.

Since PMWE are also weaker in absolute reflectivity than PMSE the small number of coherent integrations used in the scanning experiments makes it difficult to detect echoes. The event from 31 December 2010 at around 19:00 UT was strong enough to backscatter signals from all transmitted directions down to $15^{\circ}$ off-zenith. Figure 5 shows horizontally resolved structures of a PMWE at different heights. The maximum scaling of the color coded SNR is lower by $21 \mathrm{~dB}$ compared to the plots in Fig. 3 demonstrating the much weaker strength of PMWE compared to PMSE. The vertical slice along the east-west direction shows a layered structure with a thickness of $2-3 \mathrm{~km}$ tilted by approximately $30^{\circ}$. The horizontal slices through the PMWE depict sharp gradients of SNR indicating a spatially localized process behind. A detailed discussion of this very first 3-D-observation of a PMWE is given in Rapp et al. (2011). 

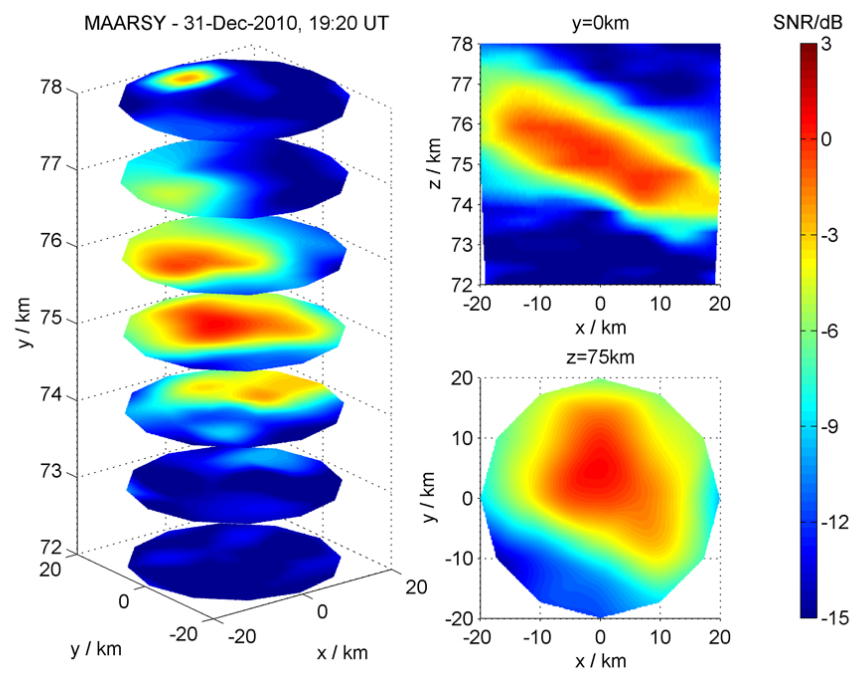

Fig. 5. 3-D structure of a PMWE quasi-simultaneously observed with 25 beams on 31 December.

\section{Summary}

The present paper describes the design and functionality of the two major stages of expansion of the Middle Atmosphere Alomar Radar System (MAARSY) during the installation in 2010. After the construction of the antenna array in summer 2009 and the installation of an initial expansion stage of 196 transceiver modules the radar operation started in May 2010. The second stage of expansion to 343 transceiver modules was brought into service in November 2010.

The major objective for building MAARSY, the investigation of horizontal structures of Polar Mesosphere Echoes, was tested with the partial systems using multi-beam experiments with up to 91 beams quasi-simultaneously during campaigns in August and December 2010. The presented first examples of horizontally resolved structures of Polar Mesosphere Summer and Winter Echoes demonstrate the performance of MAARSY and give a first insight into the three dimensional variability of PMSE and PMWE.

The final extension of MAARSY to 433 transceiver modules has recently been completed in May 2011.

Acknowledgements. The authors would like to thank IAP personnel who worked hard with the installation of MAARSY in particular Jörg Trautner, Thomas Barth, Jens Wedrich, Norbert Engler, Dieter Keuer, Marius Zecha, Hans-Jürgen Heckl, Torsten Köpnick, Manja Placke, and Qiang Li, as well as the students Ding Tao, Gunnar Keuer, Christian Schernus, Sophie Latteck, Danilo Hauch and Richard Hünerjäger. We also thank S. Fukao, T. Sato and M. Yamamoto for their suggestions and discussions in the early stage of planing the radar. We are indebted to the staff of the Andøya Rocket Range for their permanent support. The radar development was supported by grant 01 LP 0802A of Bundesmisterium für Bildung und Forschung. Topical Editor Matthias Förster thanks Michael Rietveld and Martin Friedrich for their help in evaluating this paper.

\section{References}

Czechowsky, P., Rüster, R., and Schmidt, G.: Variations of mesospheric structures in different seasons, Geophys. Res. Lett., 6, 459-462, 1979.

Ecklund, W. L. and Balsley, B. B.: Long-term observations of the Arctic mesosphere with the MST radar at Poker Flat, Alaska, J. Geophys. Res., 86, 7775-7780, 1981.

Kirkwood, S., Barabash, V., Belova, E., Nilsson, H., Rao, T. N., Stebel, K., Osepian, A., and Chilson, P. B.: Polar Mesosphere Winter Echoes during Solar Proton Events, Adv. Polar Upper Atmos. Res., 16, 111-125, 2002.

Kirkwood, S., Chilson, P., Belova, E., Dalin, P., Häggström, I., Rietveld, M., and Singer, W.: Infrasound - the cause of strong Polar Mesosphere Winter Echoes?, Ann. Geophys., 24, 475-491, doi:10.5194/angeo-24-475-2006, 2006.

Latteck, R., Singer, W., Rapp, M., and Renkwitz, T.: MAARSY - the new MST radar on Andøya/Norway, Adv. Radio Sci., 8, 219-224, doi:10.5194/ars-8-219-2010, 2010.

Latteck, R., Singer, W., Rapp, M., Vandepeer, B., Renkwitz, T., Zecha, M., and Stober, G.: MAARSY - The new MST radar on Andøya: System description and first results, Radio Sci., 47, RS1006, doi:10.1029/2011RS004775, 2012.

Lübken, F.-J., Strelnikov, B., Rapp, M., Singer, W., Latteck, R., Brattli, A., Hoppe, U.-P., and Friedrich, M.: The thermal and dynamical state of the atmosphere during polar mesosphere winter echoes, Atmos. Chem. Phys., 6, 13-24, doi:10.5194/acp-6-132006, 2006.

Rapp, M. and Lübken, F.-J.: Polar mesosphere summer echoes (PMSE): Review of observations and current understanding, Atmos. Chem. Phys., 4, 2601-2633, doi:10.5194/acp-4-2601-2004, 2004.

Rapp, M., Latteck, R., Stober, G., and Singer, W.: First 3dimensional observations of polar mesosphere winter echoes: resolving space-time ambiguity, J. Geophys. Res., 116, A11307, doi:10.1029/2011JA016858, 2011.

Renkwitz, T., Singer, W., Latteck, R., and Rapp, M.: Multi beam observations of cosmic radio noise using a VHF radar with beam forming by a Butler matrix, Adv. Radio Sci., 9, 349-357, doi:10.5194/ars-9-349-2011, 2011.

Zeller, O., Zecha, M., Bremer, J., Latteck, R., and Singer, W.: Mean characteristics of mesosphere winter echoes at mid- and highlatitudes, J. Atmos. Sol.-Terr. Phy., 68, 1087-1104, doi:10.1016/ j.jastp.2006.02.015, 2006. 